\title{
Em terras nordestinas: $A$ história do amor de Fernando e Isaura - resíduos do medievo
}

Aline Leitão Moreira ${ }^{1}$

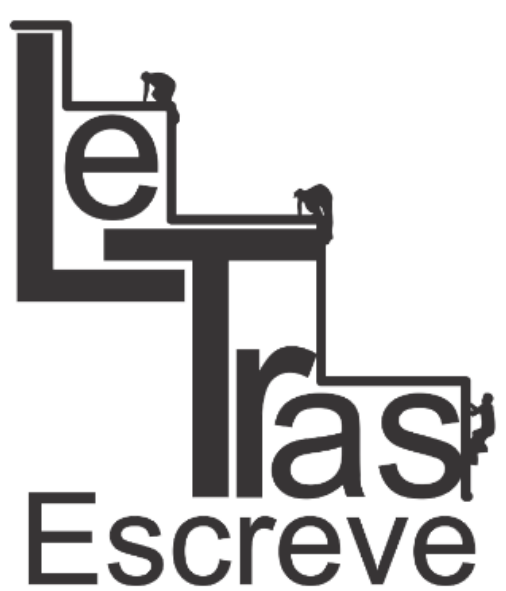

(ISSN 2238-8060)

Resumo: A história do amor de Fernando e Isaura é um romance de Ariano Suassuna, escrito com o intuito de rememorar a triste e bela história de Tristão e Isolda, os conhecidos amantes das Cornualhas. Ariano Suassuna criou uma versão nordestina da narrativa permeada de resíduos do medievo, através da caracterização das personagens, da concepção do amor, da honra e da traição.

Palavras-Chave: Romance. Medievo. Residualidade.

Resumen: A história do amor de Fernando e Isaura, es una novela escrita por Ariano Suassuna para recordar la historia triste y hermosa de los amantes de Cornualhas. En la preparación de una versión nordestina de la narrativa, Ariano Suassuna utiliza residuos de la Edad Media, a través de la caracterización de los personajes, la concepción del amor, honor y traición.

Palabras Clave: Romance. Medieval. Residualidad.

"O homem é igual em qualquer canto, em qualquer época. O que varia são as circunstâncias através das quais cada comunidade realiza o humano."

Ariano Suassuna

A história do amor de Fernando e Isaura é uma versão brasileira do Romance de Tristão e Isolda, como o diz Ariano Suassuna em Advertência ${ }^{2}$, foi escrita a partir da sugestão do amigo Francisco Brennand e no intento de exercício no gênero romance.

Mais que isso, Ariano confessa:

Sou um escritor de poucos livros e de poucos leitores. Vivo extraviado em meu tempo por acreditar em valores que a maioria julga ultrapassados. Entre esses, o amor, a honra e a beleza que ilumina os difíceis caminhos da retidão, da superioridade moral, da elevação, da delicadeza, e não da vulgaridade dos sentimentos. Não sei, portanto, que interesse haverá, principalmente para a juventude, numa história tão fora

\footnotetext{
1 Mestre em Letras pela Universidade Federal do Ceará. E-mail: alineleitaomoreira@yahoo.com.br

${ }^{2}$ SUASSUNA, Ariano. "Advertência". In: SUASSUNA, Ariano. Op.cit., 2009, p. $19-20$.
}

https://periodicos.unifap.br/index.php/letras

Macapá, v. 6, n. I, Io semestre, 2016. 


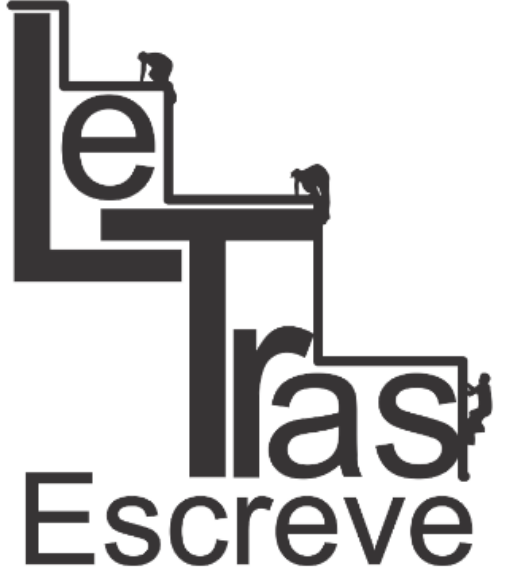

(ISSN 2238-8060) de moda quanto esta. (...) Por outro lado, tenho ainda, o infortúnio de escrever movido pela paixão e pela compaixão, atitude também deslocada neste tempo de autores frios, lúcidos e impiedosos. Lembro, então, aos eventuais leitores desta história que, narrada em 1956, sua ação decorre em ano ainda mais recuado. Por isso, encarem com indulgência os arcaicos escrúpulos de seus personagens, perdoando remorsos e hesitações que, menos do que a eles, pertencem ao co-autor contemporâneo desta história tão antiga. ${ }^{3}$

Ao dar este depoimento, o autor não só confere à obra um valor algo antigo, o que vem a denominar de "arcaicos escrúpulos", como se intitula apenas co-autor dessa história. Ao fazer isso, Suassuna confirma sua filiação à fonte na qual bebera, a obra $O$ Romance de Tristão e Isolda, que por sua vez é uma versão baseada em textos medievais e residualmente aproveita o material celta.

Entendemos por arcaico o que passou e ficou para trás. Esses valores aos quais nos remete Suassuna são antigos e residuais, mas não arcaicos porque continuam conjugando força na atualidade, não fosse assim não os buscaríamos na atualidade. A esse respeito, Raymond Williams, posiciona-se:

Por "residual" quero dizer alguma coisa diferente do "arcaico", embora na prática seja difícil, com frequência, distingui-los. Qualquer cultura inclui elementos disponíveis do seu passado, a ser observado, examinado, ou mesmo, ocasionalmente, a ser "revivido" de maneira consciente, de uma forma deliberadamente especializante. O que entendo pelo "residual" é muito diferente. O residual, por definição, foi efetivamente formado no passado, mas ainda está ativo no processo cultural, não só como um elemento do passado, mas como um elemento efetivo do presente. Assim, certas experiências, significados e valores que não se podem expressar, ou verificar substancialmente, em termos da cultura dominante, ainda são vividos e praticados à base de resíduo - cultural bem como social - de uma instituição ou formação social e cultural anterior. ${ }^{4}$

Desse modo, Ariano ao escrever A História do amor de

${ }^{3} / d$. Ibidem, p. $19-20$.

4 WILLIAMS, Raymond. Marxismo e Literatura. Rio de Janeiro: Zahar, 1979, p. 125.

https://periodicos.unifap.br/index.php/letras

Macapá, v. 6, n. I, Io semestre, 2016. 


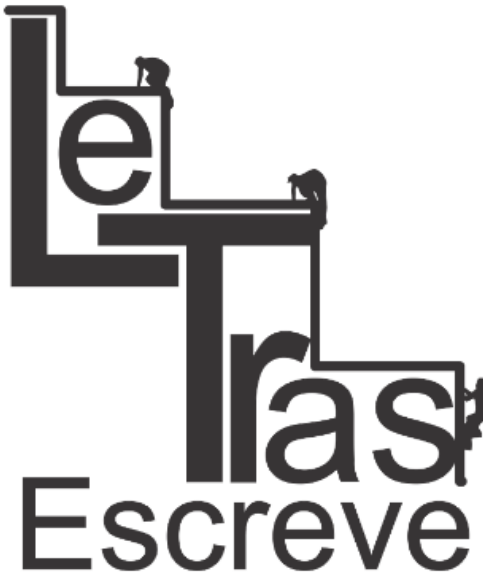

(ISSN 2238-8060)

Fernando e Isaura atualiza as narrativas de Tristão e Isolda ao retomar resíduos do medievo.

No romance $A$ história do amor de Fernando e Isaura a principal ambientação é a fazenda São Joaquim, pertencente a Marcos, tio de Fernando. A propriedade "estendia-se entre Penedo e Piassabussu, por uma vasta região, coberta de coqueiros na faixa da praia e na foz do Rio São Francisco" ${ }^{5}$. Marcos era um homem de posses e criara Fernando. De certo modo, a Fazenda São Joaquim, retoma a fortaleza de Tintagel, costa ocidental da Cornualha, onde Marcos, tio de Tristão, é rei.

Ariano Suassuna recorre a vários pontos de encontro para assemelhar as duas narrativas. Já agora, podemos elencar alguns: a ambientação das narrativas, o nome do tio e o nome de Fernando, a guardar, na essência, o mesmo significado que Tristão ${ }^{6}$. Suassuna, no entanto, com relação ao nome de Isolda, retoma apenas o que podemos visualizar na forma escrita ou através do som da palavra. Isaura, é assim, um nome parecido com Isolda, sem contudo assemelhar-se na significação.

Também, e principalmente recorrentes, serão os valores morais das personagens. Fernando é apaixonado por Isaura, apesar do respeito e do amor que sente pelo tio. Já Isaura, apesar da admiração sentida pelo esposo, não consegue resistir à paixão. $E$ ambos passam a ter encontros furtivos de amor à revelia das convenções sociais impostas pelo casamento, à revelia dos sentimentos de Marcos.

A história do amor de Fernando e Isaura é uma obra de Ariano Suassuna muito diferente das suas demais, pois grande parte de seu fazer literário está para o teatro, bem como, quase todas as ambientações são o sertão. Aqui o cenário é o litoral "úmido, fértil e chuvoso"7, fazendo referência ao Sertão somente na segunda

\footnotetext{
${ }^{5}$ SUASSUNA, Ariano. Op.cit., 2009, p. 13.

${ }^{6}$ Segundo a onomástica, tanto Tristão, como Fernando são nomes que dizem respeito à inteligência e força.

7 TAVARES, Bráulio. ABC de Ariano Suassuna. Rio de Janeiro: José
} 
metade, mas mesmo assim, o "Sertão à beira-rio"8. A obra, segundo Bráulio Tavares,

É uma história de amor com a intensidade das tragédias teatrais e com a sucessão de peripécias e complicação dos romances de cordel como A Força do Amor ou Alonso e Marina. O estilo é outro, a ambientação é outra, e principalmente a voz narrativa é lírica, compassada, contemplativa, nada tem a ver com a voz de Quaderna. Nada de regionalismos, embora a história se passe na região do São Francisco, entre Alagoas e Pernambuco. É uma história de amor, sensual e trágica, cheia de sinceridade e pureza, como não existe no Romance d'A Pedra do Reino, onde todo sexo que existe é feito com más intenções. ${ }^{9}$

Embora seja a referida obra uma espécie de exceção, quanto à temática, à ambientação, à forma e até ao modo do fazer literário de Ariano, há, sem dúvida, algo que não foge à proposta do escritor

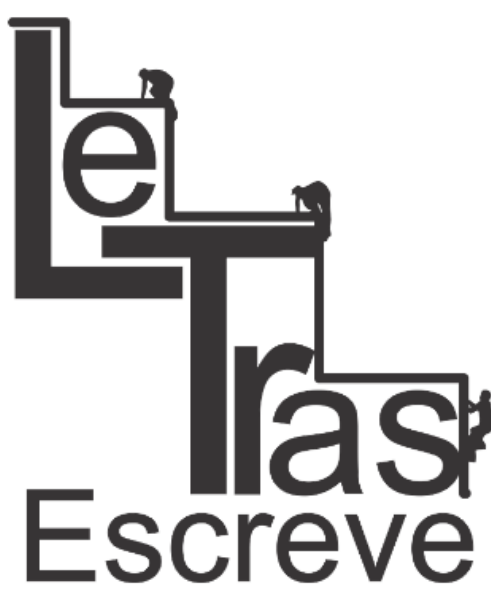

(ISSN 2238-8060) paraibano: a medievalidade, que se apresenta aqui tanto quanto se realiza em outras obras suas, fonte que bebera em sua matriz.

O Romance de Tristão e Isolda é a fonte na qual baseou-se Ariano para a feitura d'A história do amor de Fernando e Isaura, e, embora esta seja uma obra sem par no contexto literário suassuniano, há a visualização de aspectos tipicamente medievais, como ocorre no desenvolver de toda sua obra.

Ligia Vassalo aborda as origens européias, referindo-se à medievalidade na obra teatral do escritor paraibano. Para nós, embora se tratando do teatro e não do romance suassuniano, esta obra também será de grande valor por abarcar características medievais também presentes na obra de nossa análise.

Vassalo nos fala da importância de recolher alguns aspectos da cultura europeia na passagem da Idade Média para o Renascimento ${ }^{10}$, porque vários deles se transmitem às Américas.

Olympio, 2007, p. 94.

8 Id. Ibidem.

9 TAVARES, Bráulio. Op. Cit., p. 94.

10 Há autores que não aceitam essa repartição entre Idade Média e Renascimento, pois haveria apenas Idade Média. Vassalo, porém, utiliza essa nomenclatura.

https://periodicos.unifap.br/index.php/letras

Macapá, v. 6, n. I, Io semestre, 2016. 
Esses aspectos moldam tanto a sociedade quanto a cultura e tomam forma na produção literária não só do Nordeste, mas especialmente na de Suassuna.

Para Lígia Vassalo:

Enquanto o velho continente ingressava no mundo da escrita e da indústria, emigrou para a América aquele da voz e, com ele, a superestrutura intelectual que o acompanha. Ele não é um resíduo estratificado sobrevivente na memória de alguns, mas é vivo e atuante na prática dos contadores de histórias, nos improvisos dos cantadores, nos folhetos de cordel capazes de incorporar a cada instante novos eventos do cotidiano. A cultura oral nordestina consome ainda hoje temas e técnicas medievalizantes, como as histórias de procedência árabe ou francesa, junto com os desafios dos cantadores, a estrofação e várias modalidades de versejar ${ }^{11}$.

A autora nos fala de um resíduo "vivo e atuante" com

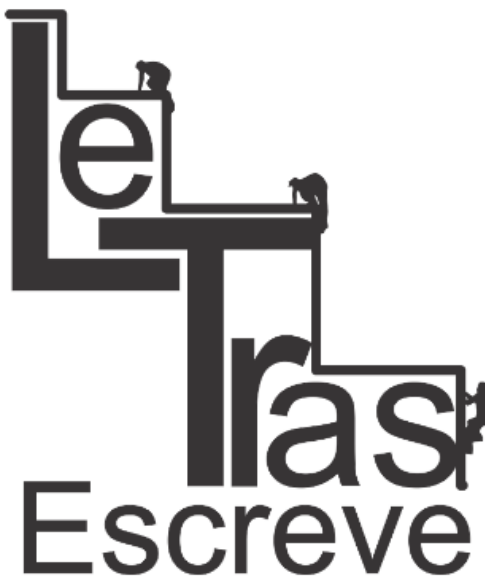

(ISSN 2238-8060)

Resíduos são aquilo que remanesce de uma época para outra e tem a força de criar de novo toda uma cultura, toda uma obra. $O$ resíduo é dotado de extremo vigor. Não se confunde com o antigo. É a expressão surgida com a força do novo porque é uma cristalização. É algo que se transforma, como o material bruto tornado jóia na lapidação. ${ }^{12}$

Além do termo residualidade defendido por Pontes, também é interessante analisar o termo intertextualidade, cunhado por Julia

\footnotetext{
11 VASSALLO, Lígia. O Sertão Medieval: origens européias do teatro de Ariano Suassuna. Rio de Janeiro: Francisco Alves, 1993, p. 163.

12 PONTES, Roberto. Reflexões sobre Residualidade. Comunicação na Jornada Literária "A Residualidade ao alcance de todos". Departamento de Literatura da UFC, Fortaleza, julho de 2006, sob forma de entrevista concedida à Rubenita Alves Moreira, no dia 05 de Junho de 2006, p.4.
}

https://periodicos.unifap.br/index.php/letras

Macapá, v. 6, n. I, Io semestre, 2016. 


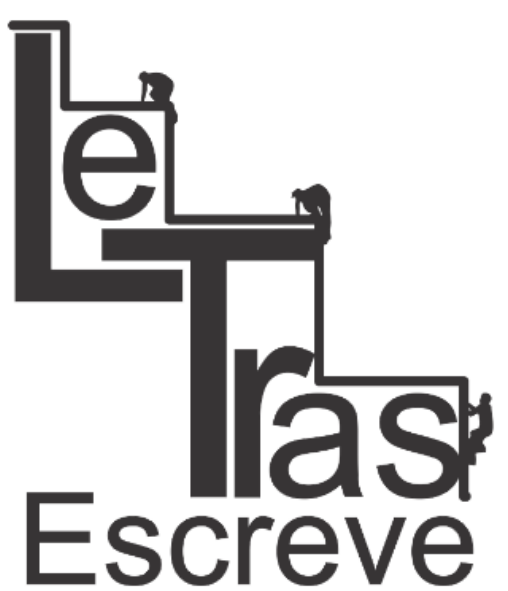

(ISSN 2238-8060)
Kristeva no final da década de 1960 a partir dos estudos de Bakhtin, para nomear a interatividade entre dois ou mais textos. Para a autora, o texto é uma produtividade, ou seja, no espaço de um texto se cruzam e se neutralizam vários enunciados, tomados de outros textos.

A intertextualidade se refere ao conhecimento prévio de outros textos. Sendo assim, o nível intertextual é um reflexo da bagagem de experiência e cultura do escritor e do leitor.

Portanto há intertextualidade quando Ariano afirma ter-se baseado n'O Romance de Tristão e Isolda, escrito por Bédier no século XX para escrever $A$ história do amor de Fernando e Isaura. No entanto, ao fazê-lo o autor retoma o medievo das versões do século XII e XIII residualmente, pois parte do imaginário visualizado na obra de Bédier advém da época medieval.

Alguns dos traços mediévicos presentes no romance de Ariano são o modus vivendi, a caracterização e o modo de sentir dos personagens, a crença religiosa, o estatuto social.

A distinção entre intertextualidade e residualidade é feita por Roberto Pontes, quando se faz referência ao gato que descome dinheiro, episódio do Auto da Compadecida, o qual tem-se que remontar à sua origem na cultura ibérica moçárabe:

O próprio Ariano Suassuna no estudo publicado no livro Literatura popular em verso, v. 1, editado pela Casa Rui Barbosa, fala sobre o assunto e diz que só depois, muito depois de haver escrito o Auto veio a tomar ciência que havia aproveitado matéria proveniente da cultura árabe. Ele escreveu sem saber por que havia assimilado o episódio culturalmente. Esta é a diferença fundamental do resíduo relativamente à intertextualidade, pois o residual aparece na obra sem que o autor tenha consciência do aproveitamento do material utilizado. Isso assim ocorre porque a residualidade se dá no plano da mentalidade ${ }^{13}$ e não no do simples texto ${ }^{14}$. Esse

${ }^{13}$ A idéia de mentalidade de Roberto Pontes é trabalhada a partir dos estudos da Nova História, desenvolvidos por Georges Duby e Jacques Le Goff, entre outros, na École des Annales, cujos fundadores foram Marc Bloch e Lucien Febvre. Para o grupo da Nova História o indivíduo não pode ser estudado isolado da sociedade a qual pertence. Para Pontes, o homem como integrante de uma sociedade expressa a mentalidade do seu

https://periodicos.unifap.br/index.php/letras

Macapá, v. 6, n. I, Io semestre, 2016. 


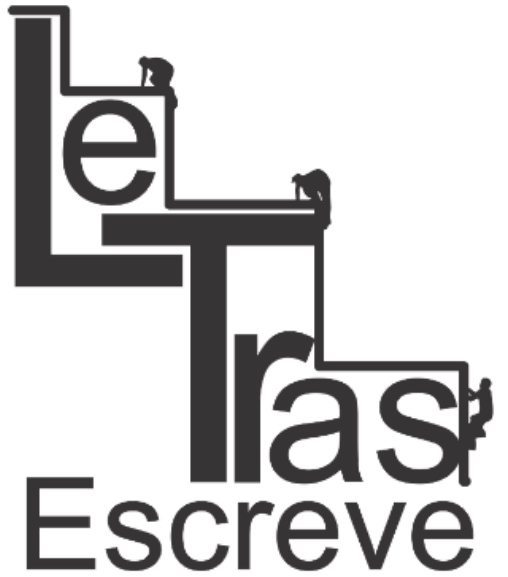

(ISSN 2238-8060)

material etnológico que nos dá a nossa raiz, a nossa identidade, Ariano pensava fosse mesmo do Nordeste. Mal sabia - seria depois esclarecido por um grande estudioso do assunto, o professor Enrique Martinez Lopez, professor de Literatura Hispânica da Universidade da Califórnia - que a história do testamento do cachorro constante no Auto era de origem moura. E assim ocorre com muitas manifestações de nossa cultura. O cuscuz, a coalhada, a técnica de fazer açúcar, o queijo, nada disso é genuinamente português nem nordestino. Todos são resíduos árabes. Assim também ocorre com a nossa cultura literária. No caso do Auto, este é a junção de uma cultura lá do Oriente com uma outra transplantada para cá, via Península Ibérica, trazendo elementos que são remanescências, resíduos, permanências. ${ }^{15}$

Pontes esclarece que a residualidade diferentemente da intertextualidade não necessariamente é retomada conscientemente, posto que diversos elementos remanescem através da mentalidade de uma determinada época.

Wilson Martins fala da origem d'A história do amor de Fernando e Isaura, repetindo uma afirmação de Ariano, que auto intitula seu primeiro romance de "imitação nordestina", de Béroul, Bédier e Afrânio Peixoto, e complementa dizendo tratar-se de uma

filiação heterogênea destinada a nacionalizar, e até a regionalizar, um dos grandes mitos do amor no Ocidente, para lembrar o título célebre de Denis de Rougemont (1906-1985). Suas origens estão, realmente, na lenda de Tristão e Isolda cuja ação se passa na Irlanda -, incorporada por Béroul à literatura universal e fonte, direta ou indireta, de Romeu e Julieta, da Princesse de Clèves e de Madame Bovary, para nada dizer, claro está, da ópera de Wagner, que a tornou paradigmática. (...) A lenda difundiu-se pela Europa a partir de 1139, através de numerosas recopilações. Joseph Bédier (1864-1938) foi autor, em 1900, de uma adaptação moderna que se tornou clássica. E Afrânio Peixoto? O seu romance é referido por Suassuna em $A$ Pedra do Reino como a história de "um rapaz e uma donzela, que não se amavam, tomaram desse vinho juntos, sem saberem do que se tratava. Na mesma

tempo. Desse modo, estudar como viviam os homens num determinado período e o que representava melhor os símbolos, os ícones, nas obras que eles deixaram dá-nos a idéia da sociedade ou o recorte histórico que eles viveram, dá-nos, portanto, a idéia da sua mentalidade.

14 Texto aqui para Roberto Pontes, diz respeito às manifestações da linguagem, como sendo apenas parte da mentalidade.

${ }^{15}$ PONTES, Roberto. Op. cit., 2006, p.4.

https://periodicos.unifap.br/index.php/letras

Macapá, v. 6, n. I, Io semestre, 2016. 


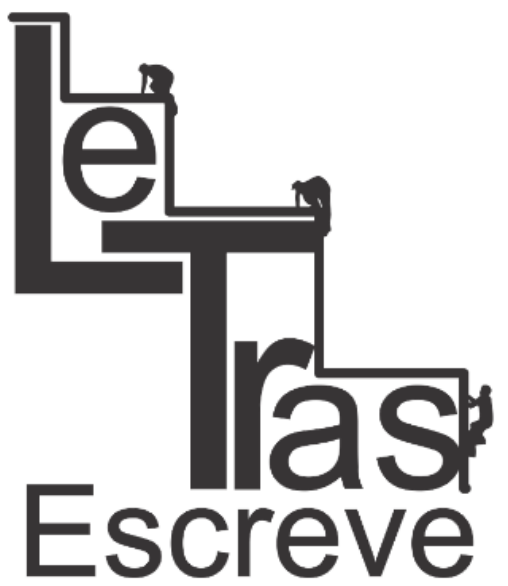

(ISSN 2238-8060)

hora, a urtiga sangrenta, venenosa, espinhenta e deleitosa do amor envolveu os dois e eles ficaram enredados de paixão para o resto da vida". Na novela de Fernando e Isaura, os dois amantes viajam na barcaça Estrela da manhã, que reaparece em A Pedra do Reino como "o mais bonito" dos navios legendários: "As velas são brancas, mas quando elas passam em Penedo, nas alagoas, desviam-se da coroa de areia vermelha onde estão os martins-pescadores flexando peixes $(\ldots) " 16$

Martins aponta, assim, intersecções entre $A$ história do amor de Fernando e Isaura e O Romance da Pedra do Reino, explicando que: "São naturais as contaminações entre os dois livros, porque a data de composição de A Pedra do Reino (1958-70) sucede imediatamente à conclusão de Fernando e Isaura".

Ainda segundo o crítico literário, Suassuna, em seu primeiro romance, do ponto de vista estilístico, filia-se muito mais a Bernardo Guimarães, que a Béroul, Thomas ou Bédier. Embora admitindo Suassuna a influência de Afrânio Peixoto, para Martins, A história do amor de Fernando e Isaura tem como resultado uma escrita convencionalmente romântica no estilo dos romances sentimentais, sem, contudo, deixar de transparecer e descodificar as inspirações mediévicas que o acompanha ${ }^{17}$. De acordo com Wilson Martins:

Com a sabedoria das visões retrospectivas, pode-se pensar que a novela de Fernando e Isaura continha em germe o Movimento armorial ${ }^{18}$, lançado por Suassuna muitos anos depois. Observei alhures que sua inspiração é a mesma de que surgiu o Félibrige na literatura francesa (1854) e o grupo The Fugitives (1922-1925) na norte-americana: recuperar o

\footnotetext{
${ }^{16}$ MARTINS, Wilson. Op.cit., p. 111-2.

${ }^{17}$ Isso provavelmente acontece porque o fascínio do amor-paixão produziu uma longa trilha de influências na literatura amorosa e serviu para fazer do tema um clichê de larga incidência no romance romântico e nas novelas de massa (onde se desfaz no entanto a trama de implicações sociais, existenciais e religiosas que o originou). (Cf: WISNIK, José Miguel. "A paixão dionisíaca em Tristão e Isolda". In: CARDOSO, Sérgio et al. Os sentidos da paixão. $3^{a}$ reimpr. São Paulo: Companhia das Letras, 1988.

18 Segundo Ariano Suassuna, o Movimento Armorial foi criado para promover o "desenvolvimento e o conhecimento das formas de expressão populares tradicionais". In: Entrevista com Ariano Suassuna. "Eu sou é Imperador". Revista Nossa História. Rio de Janeiro, dez, 2004, p. 50-55.
}

https://periodicos.unifap.br/index.php/letras

Macapá, v. 6, n. I, Io semestre, 2016. 


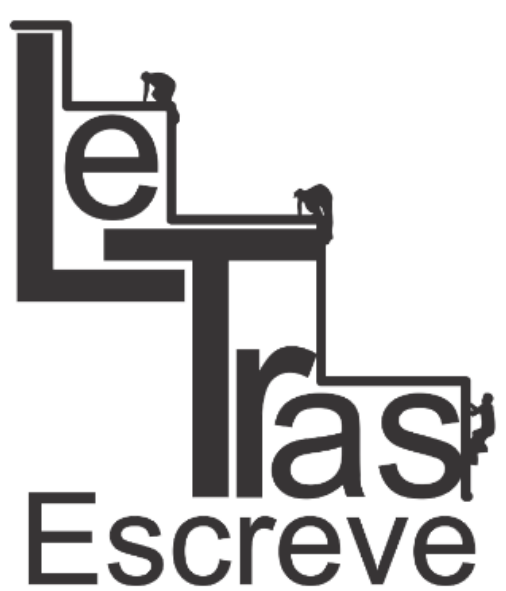

(ISSN 2238-8060) medievalismo mental, o culto da tradição (no singular), a língua regional, os valores desaparecidos. Na frança, criado por Frédéric Mistral (1830-1914), o Félibrige propunha-se a reconferir à língua d'oc e seus dialetos o prestígio que conheceram na Idade Média; compunha-se de sete poetas, a exemplo de Plêiade no século XVI, número mágico que é difícil encontrar no Félibrige, embora com programa semelhante: política conservadora, agrarismo econômico, ligações espirituais com o sentimento religioso. ${ }^{19}$

Wilson Martins, pensando sobre o Movimento armorial e o primeiro romance de Suassuna cogita que se faça alguma semelhança. No entanto, esclarece que a inspiração de Suassuna n'A história do amor de Fernando e Isaura guarda mais semelhança com os grupos Félibrige e The Fugitives, que tinham como prismas primordiais a recuperação do medievalismo mental. Segundo Ariano Suassuna, o Movimento Armorial foi criado para promover o desenvolvimento e o conhecimento das formas de expressão populares tradicionais. Para o autor,

A Arte Armorial Brasileira é aquela que tem como traço comum principal a ligação com o espírito mágico dos "folhetos" do Romanceiro Popular do Nordeste (Literatura de Cordel), com a música de viola, rabeca ou pífano que acompanha seus "cantares", e com a Xilogravura que ilustra suas capas, assim como com o espírito e a forma das Artes e espetáculos populares com esse mesmo Romanceiro relacionados. ${ }^{20}$

Assim, com vista na promoção e ampliação das formas de expressão populares e pautado basicamente nas raízes populares da cultura nordestina, o termo armorial, que etimologicamente faz referência à palavra francesa arm (arma), relacionada aos cavaleiros ou romances de cavalaria e a uma nobreza medieval, alude a brasões e insígnias de nobreza. Desse modo Ariano comunga da idéia de que havia e hoje ainda há resquícios de elementos dos romances medievais de cavalaria no Romanceiro popular e outras

\footnotetext{
${ }^{19}$ MARTINS, Wilson. Op.cit., p. 115.

${ }^{20}$ Suassuna apud SANTOS, Idelette Muzart Fonseca dos. Em demanda da poética popular: Ariano Suassuna e o Movimento Armorial. Campinas: Editora Unicamp, 1999, p. 13.
} 
manifestações culturais do Nordeste brasileiro.

Embora O Romance de Tristão e Isolda, que é matriz utilizada por Suassuna, seja considerado romance ou novela de cavalaria, por narrar os feitos heróicos do cavaleiro Tristão, não podemos dizer que a narrativa de Fernando e Isaura seja armorial, pois muito mais recupera o medievalismo mental do que inova sob o ponto de vista estético.

Estão aí fixados elementos que circundam a origem d' $A$ história do amor de Fernando e Isaura.

\section{Referências bibliográficas}

ABRANTES, Fernandel. Tristão e Isolda - Lenda Medieval Celta de

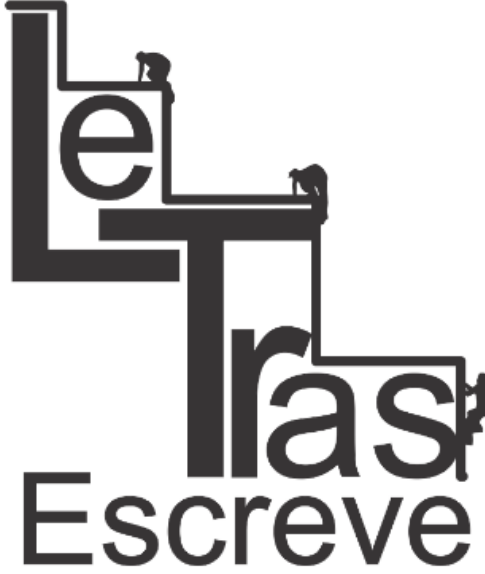

(ISSN 2238-8060) Amor. São Paulo: Martin Claret, 2007.

BARROS, Maria Nazareth Alvim de. Tristão e Isolda - O Mito da Paixão. São Paulo: Mercuryo, 1996.

BÉDIER, Joseph. O Romance de Tristão e Isolda. $1^{\text {a }}$ ed. São Paulo: Martins Fontes, 1988.

CARVALHO, Eleuda de. Cordelim de novelas da Xerazade do sertão ou Romance d"A Pedra do Reino, narrativa de mediações entre 0 arcaico e o contemporâneo. 1998. 220 f. Dissertação (Mestrado em Letras - Literatura) - Centro de Humanidades, Universidade Federal do Ceará, Fortaleza, 1998.

DUBY, Georges. "Reflexões sobre a história das mentalidades e a arte". Trad. Heloísa Jahn. In: Novos estudos CEBRAP $n^{\circ} 33$, jul/1992.

DUBY, Georges. Heloísa, Isolda e outras damas do século XII. São Paulo: Companhia das Letras, 1995.

DUBY, Georges. Idade Média, Idade dos Homens. São Paulo: Companhia das Letras, 1989.

FIGUEIREDO, Maria do Anjo Braamcamp. Tristão e Isolda. $10^{\mathrm{a}} \mathrm{ed}$. Rio de Janeiro: Francisco Alves, 1997. 
LE GOFF, Jacques. Em busca da Idade Média. Rio de Janeiro: Civilização Brasileira, 2006.

. História e Memória. $5^{\mathrm{a}}$ ed.- Campinas, São Paulo: Editora da UNICAMP, 2003.

LE GOFF, Jacques. Para um novo conceito de Idade Média. Lisboa: Editorial Estampa, 1980.

. "Trabalho, técnicas e artesãos nos sistemas de valor na Alta Idade Média". In: Para um novo conceito de Idade Média. Lisboa: Editorial Estampa, 1993.

- Uma longa Idade Média. Rio de Janeiro: Civilização Brasileira, 2008.

MARTINS, Wilson. "O romanceiro da pedra e do sonho". In: CADERNOS DE LITERATURA BRASILEIRA, $n^{\circ}$ 10. São Paulo: Instituto Moreira Sales, 2000.

NEWTON Júnior, Carlos. A ilha baratária e a ilha Brasil. Natal: UFRN. Ed. Universitária, 1995.

. "Fernando e Isaura". In: O circo da onça malhada Iniciação à obra de Ariano Suassuna. Recife: Artelivro, 2000.

- O pai, o exílio e o reino: a poesia armorial de Ariano

Suassuna. Recife: Editora Universitária UFPE, 1999.

PARIS, Gaston. "Prefácio". In: BÉDIER, Joseph. O Romance de Tristão e Isolda. $1^{a}$ ed. São Paulo: Martins Fontes, 1988.

(ISSN 2238-8060)

PONTES, Roberto. "Três modos de narrar a memória coletiva nacional". In: Anais do II Congresso da Abralic - Literatura e memória cultural, vol. 2. Belo Horizonte: ABRALIC - Associação Brasileira de Literatura Comparada. 1991, p. 149-157.

. Poesia Insubmissa Afrobrasilusa. Fortaleza: Rio de Janeiro: EUFC: Oficina do Autor, 1999.

- "Residualidade e mentalidade Trovadoresca no Romance de Clara Menina". In: Atas do III Encontro Internacional de Estudos Medievais. Rio de Janeiro: UERJ/Editora Ágora da Ilha, 2001, p. 513-516. 
"Mentalidade e residualidade na lírica camoniana". In: Escritos do cotidiano: Estudos de literatura e cultura. Publicação do Programa de Pós-Graduação em Letras-UFC. Fortaleza: 7 Sóis Editora, 2003a.

. "No Balanço da Nau Catarineta". In: XIX Encontro Brasileiro de Professores de Literatura Portuguesa, 2003, Curitica-PR. Imaginário: o não espaço do real - Anais do XIX Encontro Brasileiro de Professores de Literatura Portuguesa. Curitiba-PR : UFPR/Mídia Curitibana, 2003b. p. 913-920.

- Em torno de um resíduo: Santa Maria Egipcíaca. In: $2^{\circ}$ Colóquio do PPRLB - Relações Luso-Brasileiras; deslocamentos e permanências. Rio de Janeiro: Real Gabinete Português de Leitura, 2004, Versão eletrônica disponível em: www. realgabinete.com.br/colóquio/autor.asp?indice=62.

Acesso: 10/07/2009.

. "O viés afrobrasiluso e as literaturas de língua portuguesa". In: CHAVES, Rita; MACEDO, Tânia. (Org.). Marcas da diferença: as literaturas africanas de língua portuguesa. São Paulo: Alameda, $2006 a$.

Reflexões sobre Residualidade. Comunicação na Jornada Literária "A Residualidade ao alcance de todos". Departamento de Literatura da UFC, Fortaleza, 224 julho de 2006 b, sob forma de entrevista concedida à Rubenita Alves Moreira, em 05/06/2006 e 14/06/2006.

SUASSUNA, Ariano. A História do Amor de Fernando e Isaura. Recife: Bagaço,1994

- A História do Amor de Fernando e Isaura. $5^{\mathrm{a}}$ ed. Rio de Janeiro: José Olympio, 2009.

.Iniciação à estética. Rio de Janeiro: José Olympio, 2004.

. O Auto da Compadecida. Rio de Janeiro: Agir, 2005.

. O santo e a porca. Rio de Janeiro: José Olympio, 2006a.

. O casamento suspeitoso. Rio de Janeiro: José Olympio, $2006 b$.

https://periodicos.unifap.br/index.php/letras Macapá, v. 6, n. I, Io semestre, 2016. 


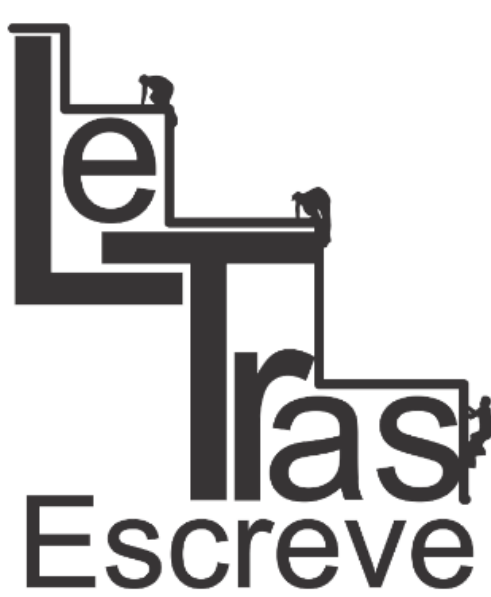

(ISSN 2238-8060)
. Romance d"A Pedra do Reino e o Príncipe do Sangue do Vai-e-Volta. $9^{\text {a }}$ ed. - Rio de Janeiro: José Olympio, 2007a. . Seleta em prosa e verso. Rio de Janeiro: José Olympio, 2007b.

. Aula Magna. João Pessoa: Editora Universitária da UFPB, 2007c.

. Almanaque Armorial. Rio de Janeiro: José Olympio, 2008.

TAVARES, Bráulio. $A B C$ de Ariano Suassuna. Rio de Janeiro: José Olympio, 2007.

VASSALLO, Lígia (Org.). A narrativa de ontem e hoje. Rio de Janeiro: Tempo Brasileiro, 1984.

VASSALLO, Lígia. O Sertão Medieval: origens européias do teatro de Ariano Suassuna. Rio de Janeiro: Francisco Alves, 1993.

WILLIANS, Raymond. Marxismo e Literatura. Rio de Janeiro: Zahar Editores, 1979.

ZUMTHOR, Paul. "Teoria literária e Idade Média". In: Ficção em debate e outros. Campinas: São Paulo: Duas Cidades: UNESP, 1979

Recebido em 10/04/2016. Aprovado em 20/05/2016. 